Jurnal Skripta, Volume 5, No 1, Februari 2019

\title{
PENINGKATAN PEMAHAMAN ORANGTUA MENGENAI RAGAM KECERDASAN ANAK BERBASIS MULTIPLE INTELLIGENCES
}

\author{
Anna Dwi Febrianti ${ }^{1}$, Khikmah Novitasari ${ }^{2 *}$ \\ ${ }^{1,2}$ Pendidikan Guru Pendidikan Anak Usia Dini \\ 1,2Universitas PGRI Yogyakarta \\ 1annaupy16@gmail.com, ${ }^{2}$ khikmah@upy.ac.id \\ *corresponding author
}

\begin{abstract}
Abstrak: Mengenali kecenderurgan kecerdasan anak menjadi suatu hal yang penting untuk dilakukan oleh orangtua dan guru untuk menentukan pendidikan yang akan diterima oleh anak. Metode dalam penelitian ini adalah penelitian eksperimen the one group pretest-posttest design. Desain ini memiliki perlakuan dan pengukuran dampak dengan melihat hasil pretest dan postest pada kelas eksperimen setelah diberikan perlakukan melalui media cerita bergambar. Subyek dalam penelitian ini adalah orangtua siswa TK ABA Patangpuluhan Kota Yogyakarta yang berjumlah 25 orang. Penelitian ini menggunakan metode quasi experiment. Penelitian ini hanya menggunakan satu kelompok tanpa ada kelompok pembanding. Teknik pengumpulan data dalam penelitian ini menggunakan tes pemahaman multiple intelligence AUD yang dikembangkan oleh peneliti. Teknik analisis data dalam penelitian ini menggunakan Uji Wilcoxon untuk melihat tingkat signifikansi dan dilakukan Uji Gain untuk mendapatkan hasil pemahaman orangtua mengenai multiple intelligence anak sebelum dan sesudah dilakukan perlakuan. Terjadi peningkatan pengetahuan orangtua mengenai multile intelligences pada anak. Dapat disimpulkan bahwa kegiatan pelatihan orangtua dalam Pendidikan anak berbasis multiple intelligences ini berhasil dan memberikan manfaat berupa peningkatan pengetahuan orangtua mengenai multiple intelligences pada anak usia dini.
\end{abstract}

Kata kunci: Multiple intelligences, Pendidikan Keluarga, Anak Usia Dini

\section{IMPROVING PARENT'S UNDERSTANDING OF THE DIVERSITY OF INTELLIGENCE OF CHILDREN BASED ON MULTIPLE INTELLIGENCES}

\begin{abstract}
:
Recognizing a child's intelligence is an important thing for parents and teachers to do to determine the education that children will receive. The method in this research is an experimental research the one group pretest-posttest design. This design has treatment and impact measurement by looking at the results of the pretest and posttest in the experimental class after being given treatment through pictorial story media. The subjects in this study were the parents of 25 students of TK ABA Patangpuluhan Yogyakarta City. This study uses a quasi experimental method. This study used only one group without a comparison group. The data collection technique in this study used the AUD multiple intelligence understanding test developed by the researcher. The data analysis technique in this study used the Wilcoxon Test to see the level of significance and a Gain Test was carried out to get the results of children's initial literacy before and after treatment. There was an increase in parental knowledge about multile intelligences in children. It can be concluded that parental training activities in multiple intelligences-based children's education are successful and provide benefits in the form of increasing parental knowledge about multiple intelligences in early childhood.
\end{abstract}

Keywords: Multiple intelligences, Family Education, Early Childhood 


\section{PENDAHULUAN}

Usia 0-6 tahun, atau yang biasa disebut sebagai usia dini adalah masa kristis seorang manusia. Dikatakan kritis, karena pada saat usia dini seluruh aspek perkembangan berlangsung sangat pesat. Pada masa ini diperlukan pendidikan yang tepat, agar pertumbuhan dan perkembangannya berjalan optimal. Pendidikan dalam hal ini menjadi salah satu hal yang mendasari keberhasilan dan kesuksesan seseorang didalam hidupnya (Astuti et al., 2016). Oleh karenanya, pendidikan yang diberikan kepada anak pada masa emas ini tentu saja harus sesuai dengan potensi yang dimiliki anak tersebut.

Setiap anak tentu memiliki potensi kecerdasannya masing-masing. Potensi kecerdasan ini hendaknya segera diketahui oleh pendidik baik orangtua maupun guru. Potensi kecerdasan ini bisa berkembang dengan baik dan menjadi gerbang kesuksesan bagi anak, atau sebaliknya potensi ini bisa mati karena tidak disadari dan tidak dirangsang dengan baik. Gardner mengungkapkan bahwa setiap anak memiliki salah satu atau lebih kecenderungan kecerdasan dari delapan kecerdasan (Multiple intelligences), yaitu; kecerdasan matematis-logis, kecerdasan musical, kecerdasan kinestetik, kecerdasan verballinguistik, kecerdasan visual-spasial, kecerdasan interpersonal, kecerdasan intrapersonal dan kecerdasan naturalis (Setiawati, 2019). Delapan kecenderungan kecerdasan tersebut sama-sama layak untuk dikembangkan. Mengenali kecenderuran kecerdasan anak menjadi suatu hal yang penting untuk dilakukan oleh orangtua dan guru untuk menentukan pendidikan yang akan diterima oleh anak. Multiple intelligencess ini, ketika diterapkan dalam pendidikan merupakan suatu teori yang memperlakukan semua peserta didik dengan perlakuan yang sama dan istimewa. Teori ini menganggap bahwa tidak ada anak yang bodoh atau pintar, yang ada yaitu anak yang menonjol dalam satu atau beberapa jenis kecerdasan. Sehingga pendidik (orangtua dan guru) harus mampu merancang metode pembelajaran yanng dapat mengoptimalkan kecerdasan anak (Masdudi, 2017).

Pendidikan yang dimaksud bukan hanya pendidikan yang dilakukan seorang guru di Taman Kanak-kanak kepada anak didiknya. Orangtua sebagai penanggungjawab utama pengasuhan anak juga berperan besar dalam pendidikan anak, terutama pendidikan anak dirumah atau pendidikan dalam keluarga. Tanggung jawab orang tua meliputi tanggung jawab keimanan, materi, fisik, moral, akal, kejiwaan, sosial, dan seks, tanggung jawab inilah yang disebut dengan bentuk Pendidikan (Andriyani, 2018). Selain itu, orang tua memiliki tanggungjawab untuk membentuk pribadi anak melalui interaksi interpersonal. Pembentukan kepribadian dengan cara tersebut akan memperlihatkan pola tingkah laku anak sesuai dengan bagaimana orang tua mengasuhnya (Raudhoh, 2017).

Pandangan mengenai pendidikan yang tepat untuk anak-anak usia dini masih beraneka ragam. pendidikan anak pada usia dini perlu dirancang sedemikian rupa agar anak tidak merasa terbebani dalam belajar (Erzad, 2018). Sampai saat ini, masih ditemui orangtua yang memaksakan anak untuk belajar membaca dan berhitung sejak dini, padahal anak tersebut menunjukkan ketidak tertarikannya pada bidang tersebut. Ketertarikan anak kepada seni sering dianggap sepele oleh orangtua. Padahal hai itu bisa menjadi penanda bahwa kecenderungan kecerdasan anak ada di bidang tersebut. Hasil tes awal mengenai pemahaman orangtua terhadap multiple intelligences pada anak usia dini menunjukkan bahwa belum semua orangtua memahami kecenderungan kecerdasan anaknya masing-masing dan masih menganggap bahwa kecerdasan matematik- 
logis merupakan kecerdasan yang harus dimiliki oleh setiap anak.

Orangtua di TK ABA Patangpuluhan kurang memahami konsep multiple intelligences pada anak usia dini. Mereka juga membutuhkan informasi yang cukup untuk mengetahui bagaimana pendidikan anak yang dapat mengakomodir kecenderungan kecerdasan masing-masing anak. Pengetahuan mengenai multiple intelligences pada anak usia dini ini, akan membantu mengarahkan orangtua dalam mendidik anak-anak mereka sesuai dengan kecenderungan kecerdasan anak. Pendidikan yang sesuai ini diharapkan dapat menumbuhkan potensi yang dimiliki anakanak tersebut menjadi gerbang kesuksesannya di masa depan. Oleh sebab itu, maka kegiatan pengabdian kepada masyarakat mengenai pemberdayaan orangtua dalam pendidikan anak berbasis multiple intelligences ini sangat dibutuhkan oleh para orangtua khususnya di lingkungan TK ABA Patangpuluhan..

Berdasarkan analisis situasi, dapat diketahui bahwa untuk menghasilkan generasi emas di masa depan, orangtua dan guru harus mengetahui kecenderungan kecerdasan anak usia dini dengan tepat. Hal ini dikarenakan masa usia dini adalah masa kritis, dimana pertumbuhan dan perkembangan otak dan fisik berlangsung sangat pesat bahkan mencapai puncaknya pada usia 0-3 tahun. Disini, permasalahan mitra adalah kurangnya inovasi orangtua sebagai penanggungjawab utama pendidikan nak dalam mengembangkan strategi pembelajaran berbasis multiple intelligences bagi anak usia dini.

\section{METODE}

Variabel yang diteliti pada penelitian ini yaitu: pelatihan Pendidikan anak dalam keluarga brbasis multiple intelligence sebagai variabel bebas atau treatment, serta kemampuan pengetahuan orangtua mengenai multiple intelligence AUD sebagai variable terikat. Subyek dalam penelitian ini adalah orangtua siswa TK ABA Patangpuluhan Kota Yogyakarta yang berjumlah 25 orang. Penelitian ini menggunakan metode quasi experiment. Metode dalam penelitian ini adalah penelitian eksperimen the one group pretest-posttest design. Desain ini memiliki perlakuan dan pengukuran dampak dengan melihat hasil pretest dan postest pada kelas eksperimen setelah diberikan perlakukan melalui pelatihan Pendidikan anak dalam keluarga berbasis multiple intelligence. Penelitian ini hanya menggunakan satu kelompok tanpa ada kelompok pembanding. Teknik pengumpulan data dalam penelitian ini menggunakan tes pemahaman multiple intelligence AUD yang dikembangkan oleh peneliti. Teknik analisis data dalam penelitian ini menggunakan Uji Wilcoxon untuk melihat tingkat signifikansi dan dilakukan Uji Gain untuk mendapatkan hasil literasi awal anak sebelum dan sesudah dilakukan perlakuan.

\section{HASIL DAN PEMBAHASAN}

Sebelum dilakukan kegiatan pelatihan orangtua mengenai pendidikan anak berbasis multiple inteligences, dilakukan pre-test pemahaman orangtua terhadap multiple intelligences pada anak usia dini. Pada pre test ini, orangtua diberikan lima pertanyaan berupa pilihan ganda. Masing-masing pertanyaan beserta hasil analisisnya dapat dilihat pada table 2. Pelaksanaan kegiatan pengabdian kepada masyarkat meliputi: 1) Pembekalan dalam pengabdian dilaksakan selama dua kali, yaitu pemberian materi mengenai teori multiple intelligences dan bagaimana pendidikan anak dalam keluarga berbasis multiple intelligences. 
Tabel 1. Jadwal Kegiatan Pengabdian

\begin{tabular}{|c|c|c|}
\hline Waktu & Kegiatan & Penanggungjawab \\
\hline 1 April s.d 15 April 2020 & Persiapan & Tim Pengabdi \\
\hline $\begin{array}{r}\text { Sabtu, } 18 \text { April } 2020 \\
\text { Pukul } 09.00-12.00 \text { WIB }\end{array}$ & $\begin{array}{l}\text { Pembekalan 1: } \\
\text { Materi Multiple intelligences }\end{array}$ & $\begin{array}{l}\text { Anna Dwi Febrianti } \\
\text { (Pemateri) }\end{array}$ \\
\hline $\begin{array}{r}\text { Sabtu, } 25 \text { April } 2020 \\
\text { Pukul } 09.00-12.00 \text { WIB }\end{array}$ & $\begin{array}{l}\text { Pembekalan 2: } \\
\text { Strategi pendidikan anak dalam } \\
\text { keluarga berbasis multiple } \\
\text { intelligences ( } 8 \text { kelompok } \\
\text { kecerdasan) }\end{array}$ & $\begin{array}{l}\text { Khikmah Novitasari, M.Pd } \\
\text { (Pemateri) }\end{array}$ \\
\hline $\begin{array}{r}\text { Sabtu, } 2 \text { Mei } 2020 \\
\text { Pukul } 09.00-12.00 \text { WIB }\end{array}$ & $\begin{array}{l}\text { Pendampingan 1: } \\
\text { Membuat Media Pembelajaran untuk } \\
\text { mengembangkan kecenderungan } \\
\text { kecerdasan anak }\end{array}$ & $\begin{array}{l}\text { Khikmah Novitasari, M.Pd } \\
\text { (Pemateri) }\end{array}$ \\
\hline $\begin{array}{r}\text { Sabtu, } 9 \text { Mei } 2020 \\
\text { Pukul } 09.00-12.00 \text { WIB }\end{array}$ & $\begin{array}{l}\text { Pendampingan 2: } \\
\text { Praktik Membuat Media } \\
\text { Pembelajaran untuk } \\
\text { mengembangkan kecenderungan } \\
\text { kecerdasan anak di ruah masing- } \\
\text { masing }\end{array}$ & $\begin{array}{l}\text { Anna Dwi Febrianti } \\
\text { (Pemateri) }\end{array}$ \\
\hline $\begin{array}{r}\text { Sabtu, 6 Juni } 2020 \\
\text { Pukul } 09.00-11.00 \text { WIB }\end{array}$ & Evaluasi & Tim Pengabdi \\
\hline 7 s.d 20 Juni 2020 & Penyusunan Laporan & Tim Pengabdi \\
\hline
\end{tabular}

Setelah proses pelatihan dilaksanakan, selanjutnya adalah proses pendampingan. Pendampingan yang dimaksud dalam pengabdian ini yaitu pendampingan dalam penyusunan strategi dan pembuatan media untuk mendidik anak dalam keluarga berbasis multiple intelligences.
Pendampingan dalam pengabdian ini dilaksanakan selama dua kali, berbentuk konsultasi terbuka secara online melalui Whatsapp Group. Adapun proses pendampingan serta respon orangtua dapat dilihat pada gambar 2 dibawah ini. 

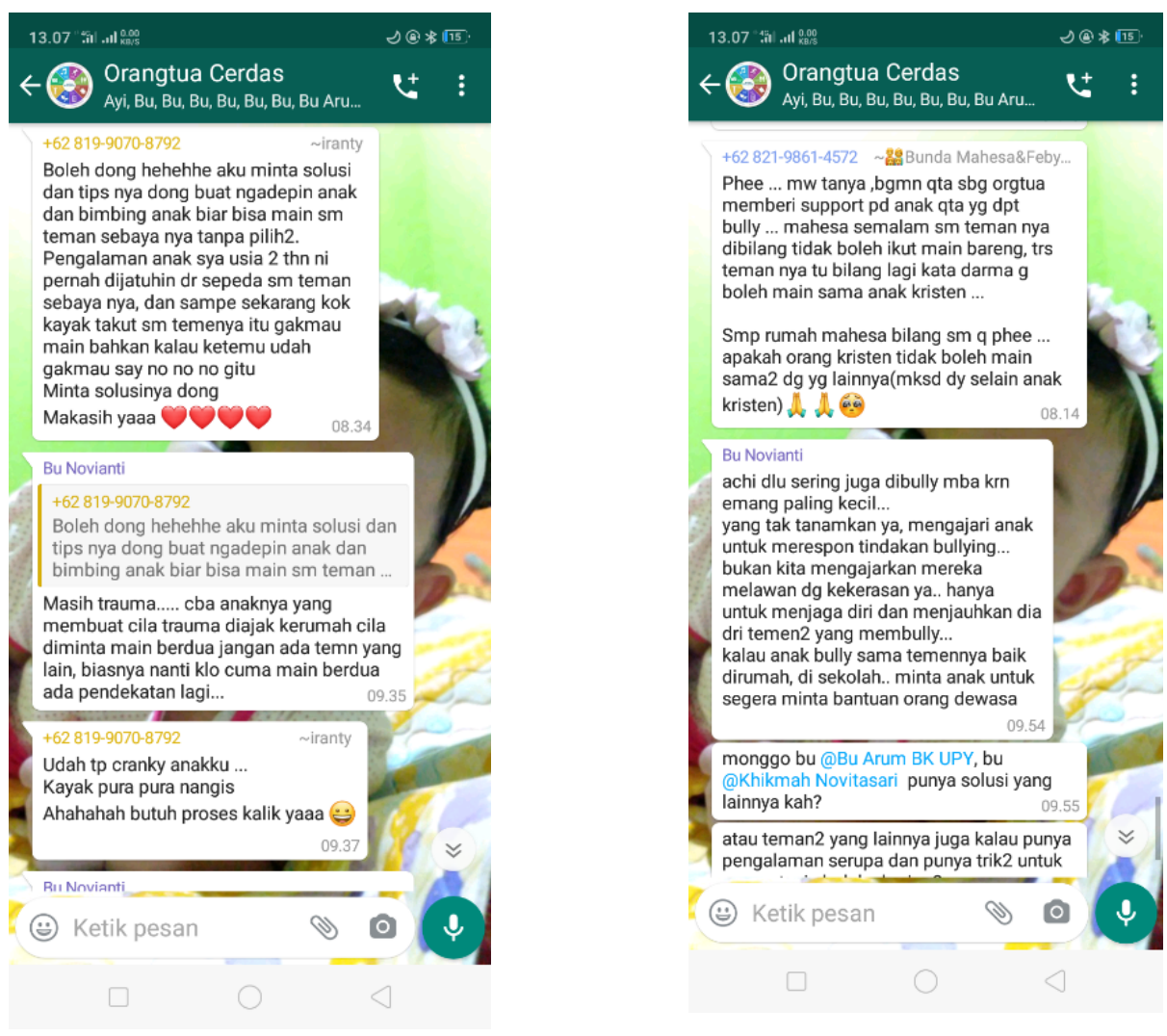

Gambar 3. Proses Pendampingan kegiatan pemberdayaan orangtua mengenai Pendidikan anak berbasis multiple intelligences

Pendampingan dilakukan, agar orangtua lebih memahami dan dapat mengimplementasikan pengetahuannya mengenai multiple intelligencec kepada anak. Pengetahuan tersebut dapat menjadi cara terbaik untuk mendidik dan berkomunikasi dengan anak yang memiliki potensi yang beragam (Abenti, 2018). Pada tahap ini, para orangtua juga diberikan kesempatan untuk praktik membuat media pembelajaran berbasis multiple intelligences. Ketika teori multiple intelligences dipraktikkan dengan memanfaatkan teknologi, maka hal tersebut menjadi cara terbaik untuk berkomunikasi dan mendidik anak dalam lingkungan apapun ( Kaewkiriya et al., 2016). 
Tabel 2. Hasil Pre Test dan Post Tes Pemahaman Orangtua Mengenai Multiple Intelligences Pada Anak

\begin{tabular}{|c|c|c|c|c|c|}
\hline \multirow[t]{2}{*}{ No } & \multirow[t]{2}{*}{ Pertanyaan } & \multirow[t]{2}{*}{ Jawaban } & \multicolumn{2}{|c|}{ Banyaknya Respon } & \multirow[t]{2}{*}{ Keterangan } \\
\hline & & & Pre test & Post test & \\
\hline \multirow[t]{4}{*}{1} & \multirow[t]{4}{*}{$\begin{array}{l}\text { Apakah arti } \\
\text { kecerdasan anak } \\
\text { menurut anda }\end{array}$} & $\begin{array}{l}\text { Memiliki keterampilan } \\
\text { dan kemampuan } \\
\text { memecahkan masalah } \\
\text { dalam bidang tertentu }\end{array}$ & 12 & 25 & \multirow{4}{*}{$\begin{array}{l}\text { Terjadi peningkatan } \\
\text { pemahaman orangtua } \\
\text { mengenai arti } \\
\text { kecerdasan pada } \\
\text { anak. Bahwa arti } \\
\text { kecerdasan adalah } \\
\text { memiliki } \\
\text { keterampilan dan } \\
\text { kemampuan } \\
\text { memecahkan } \\
\text { masalah dalam } \\
\text { bidang tertentu }\end{array}$} \\
\hline & & $\begin{array}{l}\text { Mampu menyelesaikan } \\
\text { persoalan matematika } \\
\text { dan literasi dgn baik }\end{array}$ & 6 & 0 & \\
\hline & & $\begin{array}{l}\text { Mampu memainkan } \\
\text { lebih dari } 1 \text { alat musik }\end{array}$ & 1 & 0 & \\
\hline & & $\begin{array}{l}\text { Mampu memahami diri } \\
\text { sendiri dgn baik dan } \\
\text { mampu merasakan } \\
\text { perasaan orang lain }\end{array}$ & 6 & 0 & \\
\hline \multirow[t]{7}{*}{2} & \multirow{7}{*}{$\begin{array}{l}\text { Dari kebiasaan } \\
\text { anak yang ibu } \\
\text { perhatikan } \\
\text { setiap hari, } \\
\text { apakah } \\
\text { kecenderungan } \\
\text { kecerdasan anak } \\
\text { ibu? }\end{array}$} & Visual spasial & 3 & 3 & \multirow{7}{*}{$\begin{array}{l}\text { Setelah dilakukan } \\
\text { kegiatan } \\
\text { pemberdayaan, } \\
\text { orangtua lebih bisa } \\
\text { mengenali potensi } \\
\text { anaknya }\end{array}$} \\
\hline & & Logika matematika & 5 & 7 & \\
\hline & & Verbal linguistik & 3 & 6 & \\
\hline & & Musikal & 2 & 4 & \\
\hline & & Naturalis & 1 & 1 & \\
\hline & & Interpersonal & 2 & 4 & \\
\hline & & Belum mengetahui & 9 & 0 & \\
\hline \multirow[t]{4}{*}{3} & \multirow{4}{*}{$\begin{array}{l}\text { Apakah } \\
\text { kegiatan yang } \\
\text { ibu rutinkan utk } \\
\text { anak setiap har }\end{array}$} & $\begin{array}{l}\text { Belajar berhitung dan } \\
\text { membaca }\end{array}$ & 8 & 2 & \multirow{4}{*}{$\begin{array}{l}\text { Setelah dilakukan } \\
\text { kegiatan } \\
\text { pemberdayaan } \\
\text { orangtua mengetahui } \\
\text { bahwa kebutuhan } \\
\text { anak adalah bermain, } \\
\text { dan tidak memaksa } \\
\text { anak untuk belajar } \\
\text { berhitung dan } \\
\text { membaca setiap hari }\end{array}$} \\
\hline & & $\begin{array}{l}\text { Bermain bebas sesuai } \\
\text { keinginan anak }\end{array}$ & 11 & 21 & \\
\hline & & $\begin{array}{l}\text { Membelajarkan anak } \\
\text { tentang seni }\end{array}$ & 3 & 2 & \\
\hline & & $\begin{array}{l}\text { Mengunjungi teman dan } \\
\text { guru }\end{array}$ & 3 & 0 & \\
\hline \multirow[t]{2}{*}{4} & \multirow[t]{2}{*}{$\begin{array}{l}\text { Bagaimana ibu } \\
\text { mendukung } \\
\text { kecerdasan yg } \\
\text { dimiliki anak? }\end{array}$} & $\begin{array}{l}\text { Memberikan fasilitas } \\
\text { tambahan belajar } \\
\text { mengenai hal-hal yang } \\
\text { ia sukai }\end{array}$ & 12 & 25 & \multirow{2}{*}{$\begin{array}{l}\text { Setelah dilakukan } \\
\text { kegiatan } \\
\text { pemberdayaan, } \\
\text { orangtua mengetahui } \\
\text { bahwa penting untuk } \\
\text { mendukung dan } \\
\text { memberikan fasilitas } \\
\text { tambahan belajar }\end{array}$} \\
\hline & & $\begin{array}{l}\text { Memberikan fasilitas } \\
\text { tambahan belajar utk } \\
\text { mengejar nilai anak } \\
\text { yang tertinggal }\end{array}$ & 5 & 0 & \\
\hline
\end{tabular}




\begin{tabular}{|l|l|l|l|l|l|}
\hline No & Pertanyaan & Jawaban & \multicolumn{2}{|l|}{ Banyaknya Respon } & Keterangan \\
\cline { 3 - 5 } & & Pre test & Post test & \\
\cline { 3 - 6 } & $\begin{array}{l}\text { Membiarkan potensi } \\
\text { tersebut } \\
\text { melakukan apapun }\end{array}$ & 3 & 0 & $\begin{array}{l}\text { sesuai dengan minat } \\
\text { anak }\end{array}$ \\
\hline $\mathbf{5}$ & $\begin{array}{l}\text { Belum mengetahui } \\
\text { potensi anak }\end{array}$ & 5 & 0 & \\
\hline $\begin{array}{l}\text { Apakah } \\
\text { menurut } \\
\text { pendapat ibu } \\
\text { setiap } \\
\text { kecerdasan } \\
\text { anak, harus } \\
\text { dikembangkan } \\
\text { dengan cara } \\
\text { yang sama? }\end{array}$ & Ya & 2 & 0 & $\begin{array}{l}\text { Orangtua } \\
\text { mengetahui sejak } \\
\text { awal bahwa masing- } \\
\text { masing kecerdasan } \\
\text { anak berbeda cara } \\
\text { mengembangkannya. }\end{array}$ \\
\cline { 2 - 5 } & Tidak & 23 & 25 & \\
\hline
\end{tabular}

Hasil pre test menunjukkan bahwa orangtua belum memahami kecenderungan kecerdasan masing-masing anak berbedabeda. Orangtua masih menganggap bahwa anak yang cerdas adalah anak yang dapat menyelesaikan soal matematika dengan tepat. Padahal, itu hanya salah satu kecenderungan kecerdasan yang dimiliki anak. Belum semua orang tua di TK ABA Patangpuluhan Kota Yogyakarta mengetahui kecenderungan kecerdasan anaknya masingmasing. Kegiatan pendidikan yang dilakukan orangtua untuk anak-anaknya dirumah adalah mendampingi anak belajar berhitung dan membaca. Orangtua cenderung memberikan fasilitas tambahan belajar untuk mengejar nilai anak yang tertinggal. Padahal, nilai anak yang tertinggal tersebut dapat menjadi indicator atau petunjuk bahwa kecerdasan anak bukan dibidang tersebut melainkan dibidang lain. Pemahaman yang mendalam tentang potensi manusia juga membuat pendidikan yang berbakat secara pendidikan lebih produktif (Dai, 2018). Disini orangtua sudah mengetahui bahwa mengembangkan kecerdasan anak tidak dapat disamakan antara anak yang satu dengan yang lainnya, namun, belum menyadari bahwa kecerdasan anak perlu dikembangkan sesuai dengan potensinya masing-masing.

Hasil pengabdian menunjukkan bahwa ada peningkatan pemahaman orangtua mengenai multiple intelligences pada anak usia dini. Peningkatan pemahaman ini diharapkan dapat menjadi awal pemberian pendidikan yang tepat untuk anak dirumah sesuai dengan kecenderungan kecerdasan yang dimiliki anak tersebut. Pendidikan yang tepat ini akan membantu anak untuk meraih kesuksesan dimasa yang akan datang. 


\section{KESIMPULAN}

Kegiatan pelatihan orangtua dalam Pendidikan anak berbasis multiple intelligences di TK ABA Patangpuluhan Kota Yogyakarta ini bertujuan untuk memberikan pemahaman kepada orangtua mengenai pentingnya mengenali multiple intelligences kepada anak. Kegiatan ini telah dilaksanakan sesuai dengan jadwal yang direncanakan. Terjadi peningkatan pengetahuan orangtua mengenai multile intelligences pada anak. Dapat disimpulkan bahwa kegiatan pelatihan orangtua dalam Pendidikan anak berbasis multiple intelligences di TK ABA Patangpuluhan Kota Yogyakarta ini berhasil dan memberikan manfaat berupa peningkatan pengetahuan orangtua mengenai multiple intelligences pada anak usia dini.

\section{DAFTAR PUSTAKA}

Abenti, H. F. (2018). How do I teach you? An examination of multiple intelligences and the impact on communication in the classroom. Language and Communication, 73, 29-33.

https://doi.org/10.1016/j.langcom.2 020.04.001

Andriyani, I. N. (2018). Pendidikan Anak dalam Keluarga di Era Digital. Fikrotuna, 7(1), 789-802. https://doi.org/10.32806/jf.v7i1.318 4

Astuti, W. T., Tk, G., Harapan, T., Ngaglik, T., \& Yogyakarta, S. (2016). Pembelajaran Anak Usia Dini Berbasis Multiple Intelligences di TK Tunas Harapan Tambakrejo Ngaglik Sleman. Jurnal Pendidikan Madrasah, 1(2), 257-276. http://ejournal.uinsuka.ac.id/tarbiyah/index.php/JPM/ article/view/1211

Dai, D. Y. (2018). Introduction to the Special Issue on Rethinking Human Potential: A Tribute to Howard Gardner*. Journal for the Education of the Gifted, 43(1), 3-11. https://doi.org/10.1177/0162353219 892101

Erzad, A. M. (2018). Peran Orang Tua Dalam Mendidik Anak Sejak Dini Di Lingkungan Keluarga. ThufuLA: Jurnal Inovasi Pendidikan Guru Raudhatul Athfal, 5(2), 414. https://doi.org/10.21043/thufula.v5i 2.3483

Kaewkiriya, T., Utakrit, N., \& Tiantong, M. (2016). The Design of a Rule Base for an e-Learning Recommendation System Base on Multiple Intelligences. International Journal of Information and Education Technology, 6(3), 206-210. https://doi.org/10.7763/ijiet.2016.v 6.685

Masdudi, M. (2017). Konsep Pembelajaran Multiple Intelligences Bagi Anak Usia Dini. AWLADY: Jurnal Pendidikan Anak, 3(2), 1. https://doi.org/10.24235/awlady.v3i 2.1362

Raudhoh. (2017). Peran Keluarga dalam Pendidikan Anak Usia Dini. Harkat An-Nisa: Jurnal Studi Gender Dan Anak, 2(1), 83-108.

Setiawati, L. (2019). Pembelajaran Berbasis Multiple Intelligences. TERAMPIL: Jurnal Pendidikan Dan Pembelajaran Dasar, 6(2), 140150. https://doi.org/10.24042/terampil.v $6 \mathrm{i} 2.5180$ 